\title{
Changes within the Electroencephalogram and Increase in Mental Concentration are related to Differences in Solubulisation and Composition of Different Q10-Formulations
}

\section{Freye $\mathrm{E}^{*}$ and Strobel $\mathrm{HP}^{*}$}

Department of Galenics of the Company of Energy Development LLC, Promenade 48, 7270 Davos-Platz, Switzerland

Department of Pharmaceutical Kinetics of the Company of Energy Development LLC, Promenade 48, 7270 Davos-Platz

\begin{abstract}
Objective: Evaluate the efficacy of three different Q10 formulation (Greenspeed@, Gerimed ${ }^{\circledR}$, and Power Magic ${ }^{\circledR} \mathrm{Q} 10$ ) on changes in vigilance by as well as evaluating the error rate in the concentration and attention $\mathrm{d} 2$-test before and 1 hour after the ingestion of the Q10-solutions.
\end{abstract}

Methodology: Relative EEG changes in power spectra alpha, beta, theta and delta were measured in 15 subjects (11 males and 4 females) before and 1 hour after the ingestion of one of the three Q10 formulations. Volunteers were given any one of the Q10 formulations in a double blind cross-over design. No drop-outs were registered as volunteers were eager to increase their state of vigilance. Power spectra in the EEG- demonstrated a highly significant increase in the beta-band $(8-13 \mathrm{~Hz})$ after all three solutions, the largest after intake of the Greenspeed ${ }^{\circledR}$ and the lowest after intake of the PowerMagic ${ }^{\circledR} \mathrm{Q} 10$ preparation. This closely correlated with a reduction in error rate using the d2-concentration test, where again Greenspeed ${ }^{\circledR}$ did show the most beneficial effect, PowerMagic ${ }^{\circledR}$ Q10 rated last, while Gerimed ${ }^{\circledR}$ took a middle position. Correlation coefficient between power in the EEG beta-band and the incidence of error rate was high (spearmen rank correlation coefficient $r=-0.96$ ) suggesting that all three Q10 preparation, while differing in their degree of efficacy, were able to increase neuronal cell activity, an effect which resulted in an increase in alertness and focused attention.

Conclusion: All three Q10 preparations induced vigilance and concentration. This very likely is mediated by the increase in ATP formation within the mitochondria of neuronal cells, where Q10 is a necessary constituent within the electronic transport chain.

Keywords: Q10 formulation; Central nervous system; Electroencephalography; d2-concentration and attention test; Mitochondria

\section{Introduction}

Dietary supplements containing Q10 are constantly in the rise, as they present a necessary ingredient which activates the electrode transport chain (ETC) within the mitochondria a vital energy source of every cell. Especially in to-days world where nutrition mostly contains preprocessed carbohydrates, often with chemical additives just to soothe the palate such as monosodium glutamate, artificial coloring for freshness and so-called low fat products, which however for the sake of tastiness contain high amount of sugar, eventually resulting in a lack of necessary micronutrients for the formation of the fuel ATP (adenosine triphosphate) within every cell of the body. Because of these changes endorsed by to-days food industry and further engraved by modern fast-food behaviorism, within the past 30-50 years most necessary basic nutritional elements to sufficiently synthesize Q10 are lacking. This eventually ends up in a marked deficit resulting in a suboptimal Q10 levels, being underlined by the fact that mostly in every chronic ailment there is a significant deficit in Q10-levels. In this context it is also noteworthy that any patient taking a statin drug for high cholesterol levels, because of the blockade of the enzyme HMG-CoA reductase, this ultimately will endup in a deficit of the coenzyme Q10, as both have an upstream common pathway, which is blocked by the statin drug resulting in a cholesterollowering effect but also in an insufficient manufacture of the vital coenzyme Q10 [1,2]. Because of such HMG CoA reductase inhibition, endogenous biosynthesis of the essential co-factor coenzyme Q10, required for energy production, often is associated with impairment of organ function such as the myocardium, the liver, the brain, and/or the musculature. It therefore has become common practice that any patient on a cholesterol-lowering agent should at the same time be given a Q10 preparation, which will compensate for the coenzyme Q10 deficit.

While there is a myriad of Q10 preparations on the market there is no guarantee that this coenzyme Q10 when taken orally, eventually would pass the gut-blood barrier within the intestinal tract (the watery layer on top the enterocytes), a necessary prerequisite to get into the blood circulation. Because only when getting into the blood circulation Q10 becomes available for the cells, feeding the electronic transport chain (ETC) of mitochondria necessary for synthesis of adenosine triphosphate (ATP). We therefore set out to evaluate the efficacy of three different commonly used Q10 preparations having different additional additives for increase in efficacy and solubility. By measuring the changes within the electroencephalogram (EEG) after Q10 ingestion, it was postulated that EEG waves would reflect the passage of sufficient amounts of Q10 through the gut wall (i.e., bioavailability), but at the same time would also delineate the efficacy of the Q10 preparations on cerebral neuronal cell function. As nervous cells are in a constant need of energy and Q10 being their main driving force, any additional intake would up regulate ATP synthesis, an effect which ultimately would show up in a higher state of desynchronization of cortical waves accompanied by mental concentration.

\section{Materials and Methods}

Following explanations about the nature of the study as it would request a three-time ingestion of different types of a Q10 formulation

*Corresponding author: Freye E, MD, PhD, Department of Galenics of the Company of Energy Development LLC, Farbistrasse 3 Davos-Platz,7270, Switzerland, Tel: 0041774542477; E-mail: enno.freye@uni-duesseldorf.de

Received June 17, 2016; Accepted July 12, 2016; Published July 16, 2016

Citation: Freye E, Strobel HP (2016) Changes within the Electroencephalogram and Increase in Mental Concentration are related to Differences in Solubulisation and Composition of Different Q10-Formulations. Nat Prod Chem Res 4: 233. doi:10.4172/2329-6836.1000233

Copyright: $\odot 2016$ Freye E, et al. This is an open-access article distributed under the terms of the Creative Commons Attribution License, which permits unrestricted use, distribution, and reproduction in any medium, provided the original author and source are credited. 
of supplements with no side-effects, 15 volunteers agreed to participate (11 males and 4 females with a mean age $49 \pm 15 \mathrm{SD}$, a mean height of 171 $\pm 9.6 \mathrm{~cm}$, and a mean weight of $68 \pm 13 \mathrm{~kg}$ ). Volunteers were not taking any kind of medication, they did not consume alcohol on a regular basis, ate a normal diet and did not use any drugs for recreational purposes. For continuous and computerized on-line recording of EEG-waves, volunteers were attached to two $\mathrm{Ag} / \mathrm{AgCl}$ scalp stick-on electrodes at the fronto-parietal position Fp1-A1 according to the 10/20 system [3], contralateral to their strong arm with a grounding electrode positioned at $\mathrm{FPz}$ at the medium forehead. [4]. Hooked-up to a preamplifier data were fed into a portable computerized EEG machine (Lifescan; Diatek company, San Diego, USA), which by means of aperiodic analysis, referring to zero-line crossing [5], computed the power of all electroencephalographic waves within the typical EEG spectra alpha $(8-13 \mathrm{~Hz})$, beta $(13-30 \mathrm{~Hz})$, theta $(3-8 \mathrm{~Hz})$ and delta $(0.5-3 \mathrm{~Hz})$ over a time epoch of 60 secs [6].

For comparison purposes volunteers took three different Q10 formulations together with $50 \mathrm{cc}$ of water on an empty stomach at three different occasions in a double-blind, cross-over design with a necessary time interval of 2 weeks for washout. Each of the preparations, in addition to Q10 contained different ingredients most of which were meant for increase in solubulisation and emulsification purposes consenting pharmacy standards. All three preparations were checked for any kind of contamination residues such as heavy metal, pesticides, herbicides or fungicides succumbing to strict regulatory rules of the European Food Safety commission. Independent test in laboratories for the stable concentrations of the ingredient were being conducted in order to guarantee safety and purity. The suppliers are internationally qualified and certified according to the ISO 2200 Norm in Good-Management Practice (GMP), as gene modified raw material was considered unsuitable for the production of any of these supplements containing Q10. Whenever possible the raw martial was of herbal or pure mineral origin. The three following Q10 supplements were used for the study containing different adjuncts mainly for the purpose of solubulisation:

1. Greenspeed (from SoluSwiss LLC, Davos-Platz/Switzerland) an oral solution, where the recommended $25 \mathrm{ml}$ contained the following ingredients and dosages: ubiquinone or Q10 $50 \mathrm{mg}$, Siberian ginseng extract $300 \mathrm{mg}$, vitamin $\mathrm{B}_{3}$ (nicotinamide) 48 $\mathrm{mg}$, vitamin $\mathrm{B}_{2} 4.2 \mathrm{mg}$, vitamin E $25 \mathrm{mg}$, vitamin C $160 \mathrm{mg}$ as an antioxidant and the sugar monosaccharide ribose in a dose of $1000 \mathrm{mg}$. For better reabsorption of Q10 silymarine 5 $\mathrm{mg}$, curcumin $5 \mathrm{mg}$, while the flavonoid quercetine $2 \mathrm{mg}$ was used for antioxidative purposes and chrysine $5 \mathrm{mg}$ was added because of its anti-inflammatory properties. In addition to these additives gum Arabic was used for emulsifying purposes.

2. Gerimed (from Adena Pharma, Burgwedel/Germany) a sublingual formulation, where the recommended $12 \mathrm{gtt}$ contained coenzyme Q10 in a dose of $30 \mathrm{mg}$, emulsified into glycerin, water, while red palm seed- and coconut oil which were added for solubulisation purposes, together with the emulsifier soy lecithin in a non GMO preparation.

3. Magic Power'Q10 (from LoLaFe company, Niendorf-Holstein/ Germany) taken as an oral solution, where the recommended $25 \mathrm{~mL}$ contained the following ingredients and dosages: ubiquinone or Q10 in a dose of $240 \mathrm{mg}$, NADH (or Q1) 4,2 $\mathrm{mg}$, vitamin E $160 \mathrm{mg}$, vitamin $\mathrm{B}_{12} 33 \mu \mathrm{g}$, ribose $1000 \mathrm{mg}$, plus evening primrose oil for solubulisation and glycerin plus diacetyl tartaric acid esters of mono- and diglycerides of fatty acids for emulsifying purposes.

\section{Determination of efficacy of Q10 on neuronal cells by use of different power spectra within the electroencephalogram}

Following application of the electrodes and after adaptation to a quiet surrounding, artifact-free electroencephalographic waves as derived from the subject, were fed into the EEG-computer while power was computed and matched to their appropriate power spectra alpha, beta, theta and delta over a time period of 60 secs. Following one hour after ingestion, data $\left(\mu \mathrm{V}^{2}\right)$ in the different power spectra of the electroencephalogram were computed and later printed out by a builtin printer for statistical analysis.

\section{Determining the efficacy of Q10 on mental capacity by using the $\mathrm{d} 2$-concentration and attention test}

In addition, subjects in a double-blind fashion and shortly after the EEG-session had to undergo a concentration and attention test (d2-test), which is described in detail elsewhere [7]. In short, the test consisted in stroking off the selective letter "d" with two bars on the right hand side of randomly assigned 21 targets in 14 long rows of letters of the alphabet resulting in a detail-discrimination within a specific time period of $3 \mathrm{~min}$. Thereafter hits, misses and mistakes were calculated and computed as per cent of what should have been done correctly.

\section{Statistical Analysis}

All statistical analysis was performed using the Prism 5 software for Mac OS X (Graph Pad Software Inc. San Diego, USA). In order to demonstrate any possible statistical difference within the power of the various power bands of the EEG, the one-way analysis of variance using Newman Keul's multiple comparison test was used for each power band with Bonferroni`s multiple comparison correction. For computation of statistical significance in the concentration and attention test, results of the Q10 formulation (verum) were compared with the control phase using the ANOVA Newman Keul's multiple comparison test.

The number of subjects necessary to demonstrate statistical significance was calculated presuming a $70 \%$ incidence of difference in EEG power as demonstrated elsewhere [8]. The results were taken in order to calculate the number of individuals necessary to demonstrate significant difference in EEG activity in subjects with and without the nutraceutical drink. Power analysis assumed an at least 30\% increase in the activity within the fast EEG beta- and alpha-domain following consumption of the energy drink. With a value of $\alpha=0.05$ and $\beta=0.90$ it was computed that at least 12 subjects were required in order to demonstrate significance. To minimize the effect of data loss a total of 15 volunteers were enrolled. Group differences were computed for statistical difference using the Newman Keul's multiple comparison test or the paired t-test when indicated, whichever was applicable.

Under the assumption of a non-parametric distribution, computation of a correlation between the numbers of error rates in the $\mathrm{d} 2$ test and their corresponding power in the EEG-beta domain, the Spearman correlation test was used. All statistical tests were two-sided and were considered as significant at the $\mathrm{p}<0.05$ level.

\section{Results}

EEG-power spectra are a reliable indicator as they reflect the firing rate of cortical cells which depend on the synthesis of their burning fuel within the cells, i.e., the formation of new ATP. A typical representative example of the EEG with the distribution of power within the different power spectra in the control situation is depicted in Figure 1. 
Citation: Freye E, Strobel HP (2016) Changes within the Electroencephalogram and Increase in Mental Concentration are related to Differences in Solubulisation and Composition of Different Q10-Formulations. Nat Prod Chem Res 4: 233. doi:10.4172/2329-6836.1000233

EEG-power spektra in human volunteers reflecting a relaxed state $(n=15$; mean $\pm S D)$

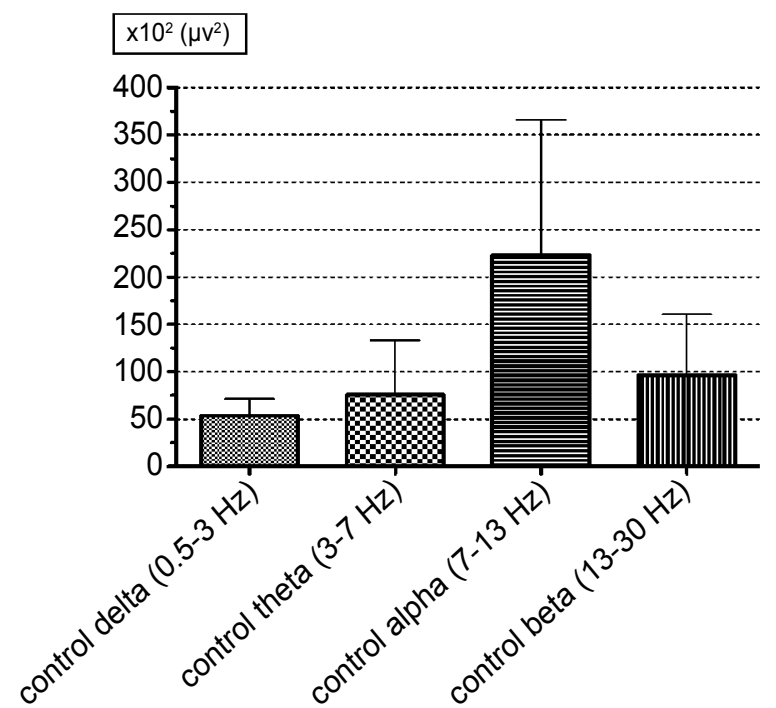

Figure 1: Representative example of the distribution of power in the differen alpha-, beta-, theta- and delta-band of the electroencephalogram in a control and relaxed state.

There, a characteristic high power in the alpha domain $(8-13 \mathrm{~Hz})$ is visualized, which reflects a relaxed and sedated state commonly ascribed to a reduced state of vigilance $[9,10]$. One hour after intake all three Q10 nutraceutical drinks when compared to control, resulted in a significant change of power within the alpha-band $(8-13 \mathrm{~Hz})$. There was a significant increase $(\mathrm{p}<0.005)$ in the Gerimed group (confidence interval 120-164) and a significant increase $(\mathrm{p}<0.01)$ after Greenspeed (confidence interval 158-205). This was in contrast to the effect of MagicPower Q10 (confidence interval 196-255) on the alpha band within the EEG as there was a marginally significant decline $(\mathrm{p}<0.05)$ in power. All 3 formulations, however demonstrated an increase of power within the fast beta-domain (13-30 Hz), a typical sign of a higher state of vigilance and sustained attention [11]. This increase was significant $(\mathrm{p}<0.01)$ after PowerMagic Q10 (confidence interval 109-139), while it was highly significant $(\mathrm{p}<0.005)$ after the Gerimed solution (confidence interval 157-249) as well as after Greenspeed (confidence interval 196-230; Table 1). At the same time, there was little but no significant change in the delta $(0.5-3 \mathrm{~Hz})-$, and the thetaband (3-8 Hz) with the exception of Power Magic'Q10, which after intake was characterized by a significant increase $(p<0.05)$ in the thetadomain (confidence interval 58-85; Table 1). These trends although seen after each of the Q10 empowered drinks was not uniform, in as much that the Greenspeed solution resulted in the highest increase in activity in the beta-domain followed by the Gerimed and thereafter by the Magic Power Q10 formulation (Table 1). There was no significant difference of increase of power the beta-band between Greenspeed and the Gerimed', both of which however demonstrated a much higher and significant increase $(\mathrm{p}<0.05)$ when compared to the MagicPower'Q10 solution (Table 1).

Such changes in EEG activity and their differences in regard to the amount of increase in power within the fast beta-domain was also reflected in the attention and concentration test (d2-test). While in the control situation mean error rate was 35.6 ( \pm SD 9.6; CI 31-40), Greenspeed induced a highly significant decline in error rate (mean
$6.3 \pm 4.9$; CI 4-8.5) one hour after intake, which is closely followed by the Gerimed preparation with a mean error rate of $22( \pm 10 \mathrm{SD}$; CI 12-30) while the Magic Power Q10 solution rated third in regard to its effectiveness in diminishing error rate with a mean of 18 ( $\pm 12 \mathrm{SD}$; CI 25-12; Figure 2). Also, better performance is reflected in the correlation coefficient between the error rate of the concentration and attention $\mathrm{d} 2$ test and the corresponding power within the beta-domain $(13-30 \mathrm{~Hz})$. There was a close correlation with an $\mathrm{R}^{2}$-value of -0.88 demonstrating high significance with a p-value of 0.001 . This greatly reflects the notion that any increase in beta activity within the cerebral cortex is reflected with an increase in attention and vigilance, data which underline an old but still valid presumption [11].

\section{Discussion}

Coenzyme Q10 (CoQ10) is a naturally occurring oil-soluble, vitamin-like substance, which is absolutely essential for optimum health and longevity. Also known as ubiquinone, CoQ10 is found in virtually every cell in the body, primarily in cellular mitochondria, being a vital component of the electron transport chain (ETC) within mitochondria, which generates 95 percent of the body's energy via

\begin{tabular}{|c|c|c|c|c|}
\hline $\begin{array}{c}\text { Control/Q10- } \\
\text { preparations }\end{array}$ & $\begin{array}{c}\text { delta-band } \\
\mathbf{0 . 5 - 3 ~ H z}\end{array}$ & $\begin{array}{c}\text { theta-band } \\
\mathbf{3 - 8} \mathbf{~ H z}\end{array}$ & $\begin{array}{c}\text { alpha-band } \\
\mathbf{8 - 1 3} \mathbf{~ H z}\end{array}$ & $\begin{array}{c}\text { beta-band } \\
\mathbf{1 3 - 3 0 ~} \mathbf{~ H z}\end{array}$ \\
\hline Control & $54 \pm 18$ & $76 \pm 58$ & $223 \pm 143$ & $97 \pm 64$ \\
& $\mathrm{Cl} 50-57$ & $\mathrm{Cl} 65-86$ & $\mathrm{Cl} 196-249$ & $\mathrm{Cl} 85-108$ \\
\hline \multirow{2}{*}{ Greenspeed $^{\circledR}$} & $59 \pm 11$ & $83 \pm 46$ & $190 \pm 65^{\star *}$ & $198 \pm 207^{\star * *}$ \\
\hline \multirow{2}{*}{ Gerimed $^{\circledR}$} & $\mathrm{Cl} 55-63$ & $\mathrm{Cl} 46-69$ & $\mathrm{Cl} 158-205$ & $\mathrm{Cl} 196-230$ \\
\hline MagicPower $^{\circledR}$ & $44 \pm 10$ & $82 \pm 58$ & $142 \pm 54^{\star * *}$ & $203 \pm 111^{\star * *}$ \\
Q10 & $44 \pm 8-48$ & $\mathrm{Cl} 58-108$ & $\mathrm{Cl} 120-164$ & $\mathrm{Cl} 157-249$ \\
\hline
\end{tabular}

Table 1: Relative amounts of power in different EEG-domains (Grand mean standard deviation and their respective confidence intervals) following different Q10 formulations, after 1 hour of intake $\left(n=15\right.$; significance level ${ }^{*} p<0.05$; ${ }^{* *} p<0.01$ or $\left.{ }^{* * *} p<0.005\right)$.

percent error rate in the $\mathrm{d} 2$-concentration \& attention test before \& after different Q10 formulations $(n=14$; mean values)

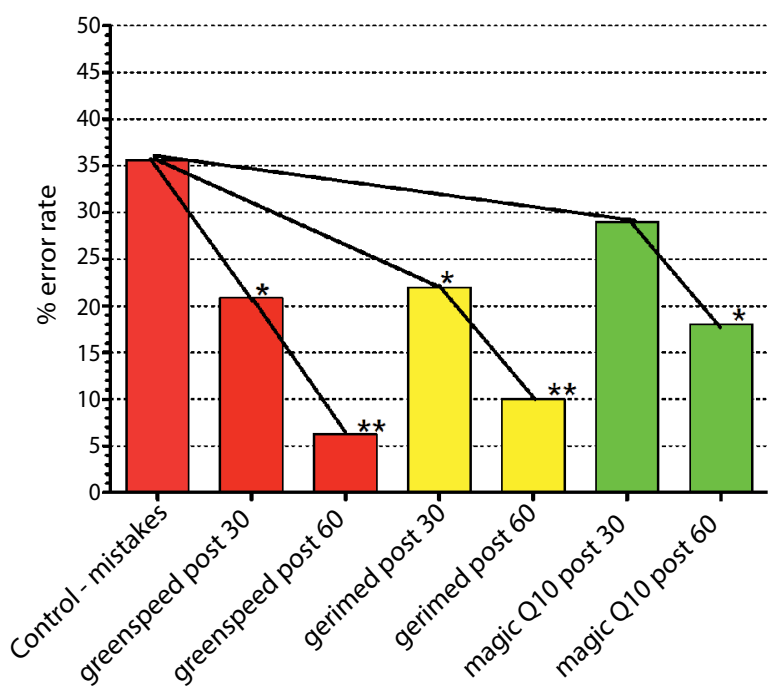

Figure 2: Mean error rate in per cent of subjects being exposed to the d2concentration and attention test before and after intake of different Q10 formulations $\left(n=15\right.$; significance level $\left.{ }^{*} p<0.05 ;{ }^{* *} p<0.001\right)$. 
synthesis of adenosine triphosphate (ATP). Organs with the highest energy requirements, such as the heart, the liver, the kidney and the brain, also have the highest concentrations of CoQ10. Therefore, adequate CoQ10 is deemed vital for mental health and flexibility. The advantageous use of CoQ10 for mental clarity is underlined by data from others who clearly demonstrated significant benefit in patients with Alzheimer, Parkinson [12,13], but also in heart failure [14], organs which are characterized by a high turnover of energy and where Q10 presents a necessary component in energy expenditure.

From our data it can be derived that all three Q10 solutions are characterized by an increase in the fast frequency beta-domain of the EEG, being the EEG band which mirrors focused attention, and a high state of vigilance [9]. Such increase in beta-activity is also reflected in the $\mathrm{d} 2$-concentration and attention test, where the Greenspeed formulation was more effective than any of the two other formulations resulting in focused attention and a scoring being the lowest in error rate, while at the same time also having a faster onset of action. These data are underlined by the fact that the other two Q10 preparations and especially Magic Power'Q10, although having the highest content of Q10, did not score highest in regard to activity on cerebral nervous cell firing rate as well as on the increase in concentration and focused attention. Such difference in efficacy of Greenspeed when compared to Magic Power Q10 needs some explanation and cannot solely be related to the monosaccharide ribose as both preparations contained similar concentrations both of which should have furnaced the ATP formation. While ribose is an essential part within the ATP particle [15] and most likely results in an additional beneficial effect by increasing the ATP synthesis in mitochondria, it does not seem to effect functionality as demonstrated by our data. Therefore, other parameters may be related to differences in efficacy one of which are the additional constituents affecting reabsorption and the formation of ATP within the cells. Such an assumption is underlined by data of a separate study where the regeneration capacity of ATP within mitochondria of leukocytes was significant $(\mathrm{p}<0.01)$ in a verum group containing the Greenspeed formulation when compared to placebo [16]. Therefore, the observed significant higher trumpeting energy turnover within the EEG, which was not seen in the other two preparations, can be attributed to the higher rate of bioavailability of Q10. In addition, it should be noted that another component within the preparation of Greenspeed ${ }^{\oplus}$, the ginseng extract with its active ingredients eleutheroside $\mathrm{A}$ and $\mathrm{E}$, can be considered an enhancer as it most likely acts as a Pgp-pump inhibitors resulting in a higher concentration of Q10 at the site of action within the cellular matrix. Such assumption is corroborated by data demonstrating that, eleutherococcus selectively inhibits p-glycoprotein drug efflux pump expression of the multidrug transporter P-glycoprotein (Pgp) system, which is encoded by the mdr1 gene being an integrated part of pharmacokinetic interactions $[17,18]$. Taken together natural antioxidants, and anti-inflammatory agents results in a higher rate of solubulisation which in combination with an inhibition of efflux out of cells leads into higher ATP formation within the neuronal tissue. By using the same preparation and as demonstrated elsewhere [16], a higher rate in synthesis of ATP can be extrapolated from our data, which also affects central nervous system activity, being mirrored in a higher firing rate of cells. This is mirrored in the EEG-beta band, an effect ensuing in an increase of cognitive function and vigilance. In this context memory and performance are executive tasks, which can be measured in the $\mathrm{d} 2$-concentration and attention test. Both mental functions improved in a manner that focused attention augmented while at the same time the capability to concentrate and subconsciously suppressing any distraction enhanced.
Since any kind of mental work puts additional demand for energy upon neuronal cells such requirement was made possible by supplementation with any one of the Q10 preparations, resulting in a surge of vigilance and an intensification in mental performance. The data of our study also underline the assumption that a higher state of vigilance and of undivided attention can be achieved with Q10, a model as originally proposed by Weeß et al. [19], where the process of mental promptness and of an adequate but also of a fast reaction results in an increase in concentration.

Why on the other hand a preparation with the highest Q10 content such as Magic Power ${ }^{\circ} \mathrm{Q} 10$, did not result in similar optimal results as seen after Greenspeed' ? The reasons for such a difference may be 2 fold:

First and utmost of all it is necessary to know that Q10 is a lipophilic compound that dissolves easily in fat which, however, is very much reluctant to pass through the watery layer of the gut or the mucous membranes of the palate to get into the bloodstream. While regular Q10 is only able to penetrate the intestinal wall by $3 \%$ of its original content [20], all efforts by the various companies are undertaken to increase this influx called bioavailability [21-23]. In the case of Greenspeed gum Arabic and various other additional components were used as to potentiate the influx and by increasing solubulisation resulting in a higher proportion of Q10 being reabsorbed, an effect which successfully has also been implemented into other formulations of Q10 [24,25]. Second, the natural compound ginseng, may have acted as a Pgp-inhibitor and as a net resulted in an increase in concentration of intracellular Q10 following intake of the Greenspeed preparation. This potential advantage in generating higher intracellular levels is in contrast to the MagicPower Q10, and also to the Gerimed" solution is being underscored by the observed changes within central nervous system activity. And in spite of the former using evening primrose oil to increase the rate rate of solubulisation together with glycerin and diacetyl tartaric acid esters of mono- and diglycerides of fatty acids for emulsifying purposes, they are however, not as effective like a Pgp-inhibitor. This connotation is underlined by data derived with the Gerimed ${ }^{\circ}$ preparation, where for solubulisation purposes red palmseed-and coconut oil together with the emulsifier soy lecithin was used, also demonstrating a lower efficacy and potency when compared to Greenspeed'. Because of such differences in the composition and in spite of its lower Q10-concentration, Greenspeed', compared to the other two Q10-compositions, induced a much higher rate in EEGchanges, a finding which is underscored by the increase in focused attention as evaluated in the $\mathrm{d} 2$-test.

In conclusion, because of differences in the solubulisation technique as well as the addition in different adjuncts in any of the three preparations, and in conjunction with the purported Pgp-inhibitor ginseng, the major denominator in efficacy of a lipophilic agent such as Q10 is the rate of penetration through membranes and its accumulation at the site of action within the mitochondria. As such, additives seem to determine the rate of solubulisation followed by an enhancement of Q10 passing through the gut wall and/or the oral cavity, both of which normally present a barrier for any lipophilic agent as they consist of hydrophilic membranes. In addition, most likely the Pgp-inhibitor may also come into play in mediating the desired effects. In this respect Greenspeed deemed superior in efficacy when compared with its two counterparts.

And lastly, it should be made clear that food sources alone may not be enough for those deficient in CoQ10. To put dietary CoQ10 intake into perspective, one pound of sardines, two pounds of beef, or two and one half pounds of peanuts, provide only $30 \mathrm{mg}$ of CoQ10. 
Citation: Freye E, Strobel HP (2016) Changes within the Electroencephalogram and Increase in Mental Concentration are related to Differences in Solubulisation and Composition of Different Q10-Formulations. Nat Prod Chem Res 4: 233. doi:10.4172/2329-6836.1000233

Fortunately, no known toxicity or side effects have been observed in any supplemental CoQ10. CoQ10 shows a moderate variability in its absorption, with some patients attaining good blood levels of CoQ10 on $100 \mathrm{mg}$ per day while others require two or three times this amount to attain the same blood level. Supplementation with CoQ10 has been studied in amounts as high as $3600 \mathrm{mg}$ per day with largely only gastrointestinal side effects observed. The observed safe level (OSL) risk assessment method indicated evidence of safety is strong at intakes of up to $1200 \mathrm{mg} /$ day.

\section{Acknowledgements}

The authors gratefully acknowledge all three companies (Solo Swiss, Adena Pharma and LoLaFe) for the generous donation of sufficient samples of their Q10-solution for making the study possible. Otherwise no other source of support was used.

\section{References}

1. Mortensen SA, Leth A, Agner E, Rohde M (1997) Dose-related decrease of serum coenzyme Q10 during treatment with HMG-CoA reductase inhibitors. Mol Aspects Med 18: S137-S144.

2. Langsjoen $P$, Langsjoe $A$ (2003) The clinical use of HMG CoA-reductase inhibitors and the associated depletion of coenzyme Q10 - A review of animal and human publications. BioFactors 18: 101-111.

3. Jasper $\mathrm{HH}$ (1958) The ten twenty electrode system of the International Federation. Electroencephalogr Clin Neurophysiol 10: 371-375.

4. Freye $E$ (2005) Cerebral Monitoring in the Operating Room and the Intensive Care Unit: An introductory for the clinician and a guide for the novice wanting to open a window to the brain. Part III: Spinal cord evoked potentials. J Clin Monit Comput 19: 169-178.

5. Spackman TN, Faust RJ, Cucchiara RF, Sharbrough FW (1987) A comparison of aperiodic analysis of the EEG with standard EEG and cerebral blood flow for detection of ischemia. Anesthesiology 66: 229-231.

6. Freye $\mathrm{E}$ (1987) Lifescan $^{\mathrm{TM}}-\mathrm{A}$ tool for monitoring. Med IQ Rev 1: 1-4.

7. Brickenkamp R (2000) Test d2 Aufmerksamkeits-Belastungs-Test. Gottingen Hogrefe.

8. Freye E, Dehnen-Seipel H, Latasch L, Behler M, Wilder-Smith OH (1999) Slow EEG-power spectra correlate with haemodynamic changes during laryngoscopy and intubation following induction with fentanyl or sufentanil. Acta Anaesthesiol Belg 50: 71-76.

9. Freye $E$ (1996) Vigilance -a state of central nervous activity being affected by centrally active drugs; its documentation by means of EEG-recording. Drager Special: Neuromonitoring, pp: 7-9.

10. Freye E, Fournell A (1988) Postoperative reversal of loss of vigilance following midazolam with the use of the antagonist flumazenil (Ro 15-1788). A comparative study with a placebo and the use of EEG-power spectra. Anaesthesist 37: 162-166.
11. Oken B, Salinsky MC, Siegward ME (2006) Vigilance, alertness, or sustained attention: Physiological basis and measurement. Clin Neurophysiol 117: 1885-1901.

12. Shults CW, Bealc MF, Songa D, Fontaine D (2004) Pilot trial of high dosages of coenzyme Q10 in patients with Parkinson's disease. Expt Neurol 188: 491-494.

13. Beal MF (2004) Mitochondrial dysfunction and oxidative damage in Alzheimer's and Parkinson's diseases and coenzyme Q10 as a potential treatment. J Bioenerg Biomembr 36: 381-386.

14. Madmani M, Yusuf Solaiman A, Tamr Agha K, Madmani Y, Shahrour Y, et al (2014) Coenzyme Q10 for heart failure. Cochrane Database Syst Rev 6.

15. Omran H, St Cyr J, Lüderitz B (2004) D-Ribose aids congestive heart failure patients. Exp Clin Cardiol 9: 117-118.

16. Freye E, Strobel HP (2015) Faster Recovery after Exercise with Phytochemicals Aimed at Mitochondrial Energy Turnover - A Double Blind Randomized Placebo Control Study in College Female Soccer Players. Int J Pharmacol Phytochem Ethnomed 1: 65-73.

17. Choi CH, Kang G, Min YD (2003) Reversal of P-glycoprotein- mediated multidrug resistance by protopanaxatriol ginsenosides from Korean red ginseng. Planta Med 69: 235-240.

18. Chen J, Raymond K (2006) The role of CYP3A4 and p- glycoprotein in fooddrug and herb-drug interactions. Aust Pharm 25: 732-738.

19. Weeß HG, Lund R, Gresele C, Böhning W, Sauter C, et al. (1998) Vigilanz, Einschlafneigung, Daueraufmerksamkeit, Müdigkeit, Schläfrigkeit. Somnologie - Schlafforschung und Schlafmedizin 2: 32-41.

20. Crane FL (2001) Biochemical functions of coenzyme Q10. J Am Coll Nutr 20: 591-598.

21. Chopra RK, Goldman R, Sinatra ST, Bhagavan HN (1998) Relative Bioavailability of coenzyme Q10 formulations in human subjects. Int J Vit Nutr Res 68: 109-113

22. Weis M, Mortensen SA, Rassing MR, Møller-Sonnergaard J, Poulsen G, et al. (1994) Bioavailability of four oral coenzyme Q10 formulations in healthy volunteers. Mol Aspects Med 25: S275-S280.

23. Molyneux S, Florkowski C, Lever M, George P (2004) The bioavailability of coenzyme Q10 supplements available in New Zealand differs markedly. N Z Med J 117.

24. Liu ZX, Artmann C (2009) Relative bioavailability comparison of different coenzyme Q10 formulations with a novel delivery system. Altern Ther Health Med 15: 42-46.

25. Schulz C, Obermüller-Jevic UC, Hasselwander O, Bernhardt J, Biesalski HK (2006) Comparison of the relative bioavailability of different coenzyme Q10 formulations with a novel solubilizate (Solu Q10). Int J Food Sci Nutr 57: 546-555. 